Cite this: RSC Advances, 2013, 3, 9690

Received 1st April 2013,

Accepted 25th April 2013

DOI: $10.1039 / c 3 r a 41714 j$

www.rsc.org/advances

\title{
Tunable surface plasmons of dielectric core-metal shell particles for dye sensitized solar cells $\dagger$
}

\author{
Bo Ding, Mengjin Yang, Bong Jae Leet and Jung-Kun Lee*
}

\begin{abstract}
Our findings show that the extinction spectrum of core-shell type plasmonic particles can be effectively controlled by changing their geometric factor. This tuning capability allows the surface plasmons of the core-shell particles to be designed in such a way that the absorption of dye molecules is maximized in dye sensitized solar cells. When plasmonic particles with a metallic nanoshell and a dielectric core are incorporated into a $\mathrm{TiO}_{2}$ mesoporous photoelectrode, the optical cross section of dye sensitizers and the energy conversion efficiency of dye-sensitized solar cells (DSSCS) are increased. The enhanced photonelectron conversion is attributed to localized surface plasmons of the core-shell particles, which increase the absorption and scattering of incoming light in the photoelectrode.
\end{abstract}

Metallic nanostructures, a new class of photonic components, have rapidly developed during the past decade. This is due to their ability to control and manipulate light at the nanoscale level, which is related on localized surface plasmons (SPs). ${ }^{1,2}$ SPs are the result of optically induced oscillations of free electrons, ${ }^{3}$ which can be coupled to the optical wave as propagating surface waves or localized excitations. SPs are strongly dependent on the topology and geometry of the metallic nanostructures. ${ }^{4-6}$ In particular, plasmonic core-shell particles, which consist of a spherical dielectric core coated with a concentric layer of metallic nanoshell, are versatile subwavelength optical components, the surface plasmon resonance of which can be tuned by simply varying the thickness of the metallic nanoshell and the diameter of the inner core. ${ }^{7,8}$ This uniquely adjustable nature of the plasmonic core-shell particles facilitates their application in surfaceenhanced Raman spectroscopy, ${ }^{9,10}$ high-resolution bioimaging, ${ }^{11,12}$ thermal therapy, ${ }^{13}$ and drug delivery. ${ }^{14}$

Recently, SPs have been extensively studied to determine their ability to enhance the light absorption of solar cells. ${ }^{15}$ Specifically, analysis has focused on the extent to which the excitation of localized SPs traps incoming photons and is coupled to light absorption capability of surrounding semiconductor. Furthermore, studies show that the effective optical path length can be dramatically increased by multiple and high-angle light scattering from the metallic nanostructures in the cell.

Department of Mechanical Engineering and Materials Science, University of Pittsburgh, Pittsburgh, PA15261E-mail: jul37@pitt.edu

† Electronic supplementary information (ESI) available. See DOI: 10.1039/ c3ra41714j

$\$$ Current address: Department of Mechanical Engineering, Korea Advanced

Institute of Science and Technology, Daejeon 301-705, South Korea.
$\mathrm{TiO}_{2}$ nanoparticle-based dye sensitized solar cells (DSSCs) have attracted a vast amount of scientific and technological interest for their potential cost effectiveness. ${ }^{16}$ However, DSSCs suffer from a relatively small optical cross section of dye molecules and a mismatch between the dye absorption spectrum and the solar spectrum. ${ }^{17-19}$ One possible way to improve the light absorption of DSSCs is to increase the thickness of the photoelectrode. However, as the photoelectrode gets thicker, carrier diffusion length becomes comparable to the thickness of the photoelectrode and carrier collection efficiency starts to decrease. ${ }^{15}$ Hence, when the photoelectrode is thicker than $20 \mu \mathrm{m}$, the effect of the photoelectrode thickness on the efficiency of DSSCs is saturated. ${ }^{20}$ In addition, the increase in the thickness of $\mathrm{TiO}_{2}$ film deteriorates open circuit voltage $\left(V_{\mathrm{oc}}\right)$ and fill factor, because of the increased back electron transfer between $\mathrm{I}_{3}{ }^{-}$ ions and conduction band electrons in $\mathrm{TiO}_{2}$ film. ${ }^{21}$

SPs have been found to be an effective way to improve the energy conversion efficiency in DSSCs without increasing the thickness of the photoelectrode, since highly increased light intensity at the near field can increase the absorption and/or scattering of incoming light. Both bare ${ }^{22}$ and surface coated metallic nanoparticles ${ }^{23-25}$ were successfully explored in DSSCs for light harvesting. However, their plasmonic frequency is pre-determined by the type of metals and less influenced by the size of the nanoparticles. Therefore, the metal nanoparticles may have difficulty in matching the frequency of the surface plasmons with the dye absorption spectrum, which depend on the unique molecular structure of dyes. $^{26-29}$ To address this problem, several groups have changed the shape of the nanostructure metals and shifted the surface plasmon frequency within the absorption spectrum of DSSCs. Chang et al. investigated the role of $\mathrm{Au}$ nanorods and demonstrate that the light absorption spectrum 
of the dye and the plasmonic frequency can be matched by changing the shape of nanostructured metal. ${ }^{30}$ Recently, we have also shown that the surface plasmons of a metal nanoshell can improve the energy conversion efficiency of DSSCs. ${ }^{31}$ The metal nanoshell couples with incoming light in wavelengths longer than the characteristic wavelength of the metal nanoparticles. Through this coupling, the core-shell structure offers us the capability to design unique plasmonic particles for different dyes, due to its optical tunability. ${ }^{32}$

In this study, we tuned the surface plasmon frequency of the core-shell particles and examined the effect on the performance of DSSCs. The absorption and scattering peaks of the core-shell particles were controlled by changing the size of the silica core. Then, the effect of surface plasmon frequency on light harvesting efficiency in DSSCs was examined using N719 dye and black dye, two commonly used photo-sensitizers in DSSCs. ${ }^{33}$ Compared with N719, the light absorption spectrum of black dye extends to a longer wavelength. Hence, the two dyes require plasmonic particles with different surface plasmon frequency in order to enhance light absorption. In order to match the absorption spectra of the N719 dye and black dye, smaller $(110 \mathrm{~nm})$ or larger (470 $\mathrm{nm}) \mathrm{Ag} @ \mathrm{SiO}_{2}$ core-shell plasmonic particles were added to the $\mathrm{TiO}_{2}$ photoelectrode. Our research has demonstrated that different core-shell particles increase the optical cross section of N719 and black dyes over red and green light via different mechanisms.

\section{Experimental procedure}

\section{Chemicals and materials}

Tetraethyl orthosilicate (TEOS, 98\%), titanium(IV) isopropoxide (TTIP, 97\%), and silver nitrate (99.8\%) were purchased from Sigma-Aldrich. Ammonium hydroxide (28\%), sodium citrate, 2-propanol, acetic acid were obtained from J. K. Baker. N719 dye, black dye, liquid electrolyte (Iodolyte AN-50), and 25 $\mu \mathrm{m}$ thick hot melt sealing tape (SX-1170-25) were bought from Solaronix. All the chemicals were used without further purification.

\section{Preparation of $\mathrm{Ag} @ \mathrm{SiO}_{2}$ core-shell particles}

$\mathrm{SiO}_{2}$ spheres with uniform diameters were synthesized by Stöber method. ${ }^{42}$ Pure ethanol, ammonium hydroxide and TEOS were mixed together, and stirred vigorously at room temperature for $24 \mathrm{~h}$. By varying the volume ratio of these chemicals, the diameter of the silica spheres could be controlled as $90 \mathrm{~nm}$ and $450 \mathrm{~nm}$ separately.

$\mathrm{Ag} @ \mathrm{SiO}_{2}$ core-shell particles were fabricated following a two-step method. ${ }^{31}$ Typically, to prepare core-shell particles with an average diameter of $110 \mathrm{~nm}, 15 \mathrm{ml}$ of freshly prepared $\left[\mathrm{Ag}\left(\mathrm{NH}_{3}\right)_{2}\right]^{+}$ion solution was added into $100 \mathrm{ml}$ aqueous solution containing $225 \mathrm{mg}$ silica nanospheres whose average diameter was $90 \mathrm{~nm}$. The mixture was then sonicated for $3 \mathrm{~h}$ at $20{ }^{\circ} \mathrm{C}$ by using the high-intensity ultrasound radiation. Resulting particles were centrifuged and washed to remove residual reagents. Purified particles were heated at $100{ }^{\circ} \mathrm{C}$ under nitrogen gas flow for $3 \mathrm{~h}$ to crystallize silver nanoparticles on the surface of $\mathrm{SiO}_{2}$ particles. After thermal annealing, the fine powder turned to be dark brown, indicating that $\mathrm{Ag}$ nanoparticles were nucleated on the surface of the $\mathrm{SiO}_{2}$ particles. These attached Ag nanoparticles were used as seeds to grow the thin silver layer on the silica cores in the future. During the second step, $27 \mathrm{mg}$ dark brown powder (Ag seeds$\mathrm{SiO}_{2}$ core) and $100 \mathrm{ml}$ aqueous solution containing $2.4 \mathrm{mM}$ silver nitrate were sequentially added into a $250 \mathrm{ml}$ three-neck bottle and mixed well. At $85{ }^{\circ} \mathrm{C}, 55 \mathrm{mg}$ sodium citrate was added into the aqueous mixture and was maintained at $85{ }^{\circ} \mathrm{C}$ for $1 \mathrm{~h}$ under vigorous stirring. After purification, $\mathrm{Ag@@iO}$ core-shell particles with an average diameter of $110 \mathrm{~nm}$ were obtained. Similarly, using different amount of chemicals, 470 nm Ag@SiO ${ }_{2}$ core-shell particles were prepared following the same route.

\section{Preparation of $\mathrm{TiO}_{2}$ nanoparticle-composite mixture films}

Anatase $\mathrm{TiO}_{2}$ nanoparticles were synthesized via a hydrothermal reaction. ${ }^{43}$ TTIP and 2-propanol were slowly dropped into a water diluted acetic acid solution at $0{ }^{\circ} \mathrm{C}$. After preheating at $80{ }^{\circ} \mathrm{C}$ for $8 \mathrm{~h}$, this solution was sealed and reacted at $230{ }^{\circ} \mathrm{C}$ for $6 \mathrm{~h}$ in a microwave accelerated reaction system (MARS, CEM Co.)

Pure $\mathrm{TiO}_{2}$ nanoparticle films and $\mathrm{TiO}_{2}-\mathrm{Ag} @ \mathrm{SiO}_{2}$ mixture films were prepared by a novel chemical sintering method. ${ }^{44} \mathrm{~A}$ small amount of aqueous solution containing Ag@ $\mathrm{SiO}_{2}$ coreshell particle was mixed well with the as-prepared $\mathrm{TiO}_{2}$ solution. The mixture solution was then condensed to $1 \mathrm{ml}$ via centrifugation. Viscous mixture paste was formed by adding several droplets of ammonium hydroxide into the condensed solution. Then, the paste was spread on FTO by doctor-blade technique and annealed at $450{ }^{\circ} \mathrm{C}$ for $30 \mathrm{~min}$ in nitrogen ambient.

\section{Fabrication of DSSCs}

Pure $\mathrm{TiO}_{2}$ film or composite film covered FTO was merged in N719 ethanol solution at room temperature for $24 \mathrm{~h}$. After drying it by nitrogen gas, the dye sensitized photoelectrode was sandwiched with thermally platinized FTO counter electrode. Between the two substrates, liquid electrolyte was filled and sealed by hot melt sealing tape.

\section{Characterization}

The microstructure of the $\mathrm{Ag} @ \mathrm{SiO}_{2}$ core-shell particles and the composite films were tested by scanning electron microscopy (SEM) (Philips XL 30) and transmission electron microscopy (TEM) (JEOL JEM-200 CX). The crystal structure of the core-shell composite particles was detected using an X-ray diffractometer (XRD) (Philips Analytical X-ray). Optical absorption and scattering spectra of the core-shell particles and the composite films were collected by UV/Vis spectrometer (Perkin Elmer, Lambda 35 UV/Vis Spectrometer) attached with an integrating sphere in the range from $300 \mathrm{~nm}$ to $900 \mathrm{~nm}$.

Photovoltaic properties of the DSSCs were measured under AM 1.5 G simulated sunlight with the aid of the electrochemical workstation ( $\mathrm{CH}$ Instruments, $\mathrm{CHI}$ 660C). The incident photon to current efficiency (IPCE) spectra of DSSCs 


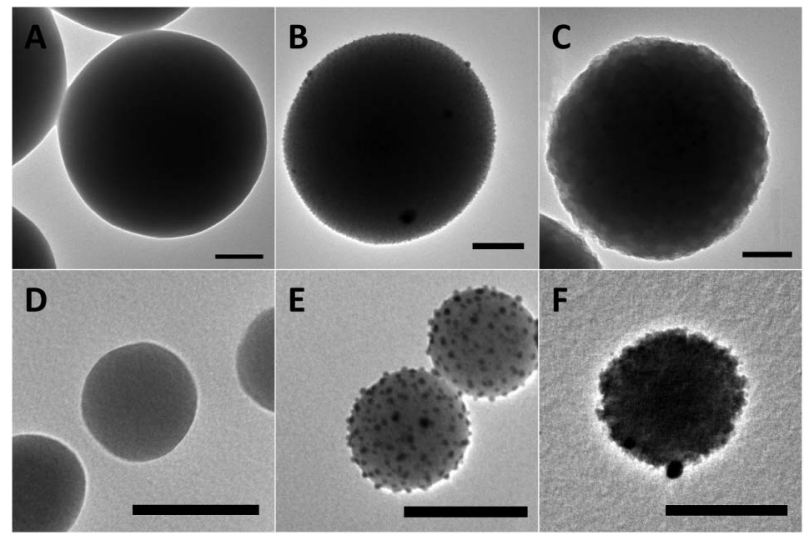

Fig. 1 TEM images of the evolution procedure of the $\mathrm{Ag} @ \mathrm{SiO}_{2}$ core-shell particles. (A) bare $\mathrm{SiO}_{2}$ sphere with a diameter of $\sim 450 \mathrm{~nm}$, (B) Ag seeds deposited $\mathrm{SiO}_{2}$ sphere with a diameter of $\sim 450 \mathrm{~nm}$, (C) $470 \mathrm{~nm} \mathrm{Ag@SiO} 2$ coreshell particle with a shell thickness of $\sim 10 \mathrm{~nm}$, (D) bare $\mathrm{SiO}_{2}$ sphere with a diameter of $\sim 90 \mathrm{~nm}$, (E) Ag seeds deposited $\mathrm{SiO}_{2}$ sphere with a diameter of

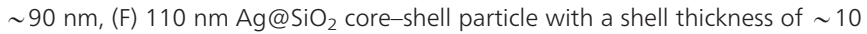
$\mathrm{nm}$ (a scale bar corresponds to $100 \mathrm{~nm}$ for all images).

was tested by illuminating the prototype device with a monochromatic beam in the visible range.

\section{Results and discussion}

Fig. 1 shows the transmission electron microscopy (TEM) images of $\mathrm{Ag} @ \mathrm{SiO}_{2}$ core-shell particles that were grown via a two-step method. The average diameter of the $\mathrm{SiO}_{2}$ core is 450 nm (Fig. 1A) or $90 \mathrm{~nm}$ (Fig. 1D). In both cases, the successful deposition of the $\mathrm{Ag}$ nanoshell was observed. In the first step of the coating, Ag nanoparticles with a diameter of 3-5 nm were attached to the surface of $\mathrm{SiO}_{2}$ particles (Fig. 1B, 1E), which would become the nucleus for further growth of the Ag shell. After the second step, a uniform Ag shell was formed. The average shell thickness of both the bigger and smaller examples was around $10 \mathrm{~nm}$.

Fig. 2 shows the extinction spectra of silica core-silver shell particles dispersed in water. In addition to the experimental UV/Vis spectra (Fig. 2A), the results of theoretical calculations are presented for comparison (Fig. 2B). In UV spectra, two peaks are found. A broad plasmon peak is found near $650 \mathrm{~nm}$ for the core-shell particles with a diameter of $110 \mathrm{~nm}$, and near $800 \mathrm{~nm}$ for the core-shell particles with a diameter of 470 $\mathrm{nm}$. The extinction of light at the red and infrared regime is the result of absorption and scattering by $\mathrm{Ag}$ nanoshells. The correlation with size clearly indicates that the wavelength of the coupled plasmon mode in core-shell particles can be controlled simply by changing the size of the core. An increase in extinction in the longer wavelength is due the size of the core-shell particles, and an appearance of the multiple peaks is attributed to a hybridization of charge oscillations at the outer and inner surfaces of the shell. ${ }^{8}$ In addition, both samples have a peak at around $410 \mathrm{~nm}$ that corresponds to the
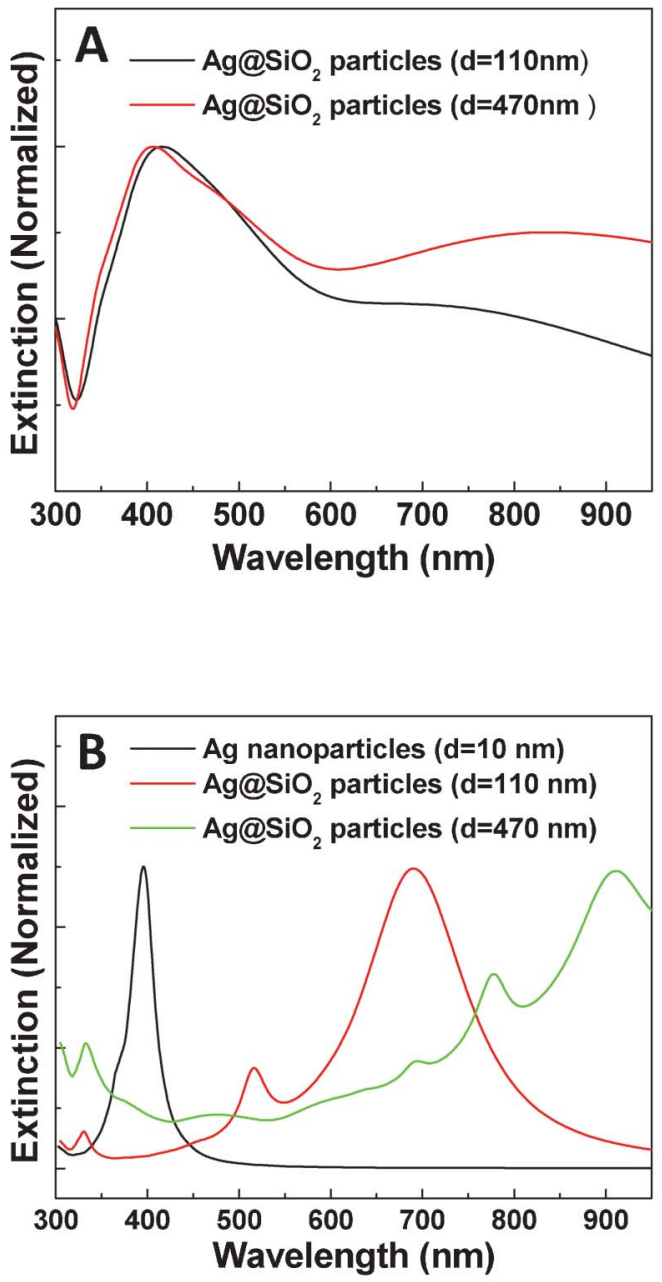

Fig. 2 UV-vis extinction spectra of 110 nm Ag@ $@ \mathrm{SiO}_{2}$ core-shell particles and 470 nm Ag@ $\mathrm{SiO}_{2}$ core-shell particles in aqueous solution (A) experimental data, (B) calculated data (a calculated spectrum of Ag nanoparticles is also added for comparison).

plasmon resonance frequency of silver nanoparticles. This shorter wavelength peak implies that $\mathrm{Ag}$ nanoshells also interact with incoming light as nanoparticles that are physically attached to the outer surface of the shell. The extinction efficiency of the metal nanoshells or metal nanoparticles was calculated via a generalized Mie scattering approach. Fig. 2B shows that the increase in the core size shifts the peak of the extinction spectrum to a longer wavelength. Similarities in the general trend between the experimental and theoretical results confirm our analysis of the experimentally measured extinction spectra of the coreshell particles. ${ }^{34,35}$ It is noted that the width of the experimentally observed plasmon peaks is broader than the width of the calculated plasmon peaks. Several factors contribute to this broadening effect in the plasmon peaks of the silver nanoshell. One is the size distribution of the silica core diameter and the silver shell thickness, and the other is surface roughness of the silver nanoshells. ${ }^{8}$ In addition, if the mean free path of the electrons is larger than the dimension of 


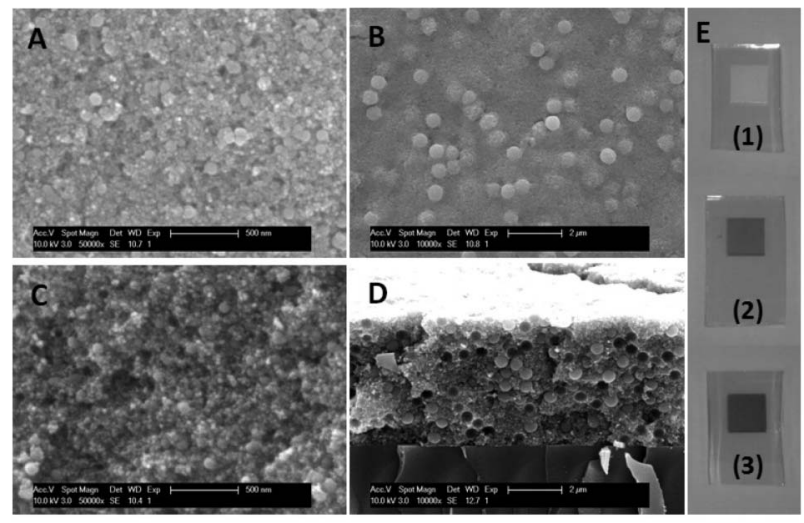

Fig. 3 (A) SEM plan-view image of 20 vol\% $110 \mathrm{~nm} \mathrm{Ag@} \mathrm{SiO}_{2}$ core-shell particles embedded $\mathrm{TiO}_{2}$ mesoporous film, (B) SEM plane-view image of 20 vol\% 470 nm Ag@SiO 2 core-shell particles embedded TiO2 mesoporous film, (C) SEM cross-section image of 20 vol\% $110 \mathrm{~nm} \mathrm{Ag@SiO} 2$ core-shell particles embedded $\mathrm{TiO}_{2}$ mesoporous film, (D) SEM cross-section image of 20 vol\% 110 $\mathrm{nm} \mathrm{Ag@SiO} 2$ core-shell particles embedded $\mathrm{TiO}_{2}$ mesoporous film, (E) an optical micrograph of photoanode coated FTO substrate. From top to bottom, the photoanode is pure $\mathrm{TiO}_{2}$ film, 20 vol\% $110 \mathrm{~nm} \mathrm{Ag@} \mathrm{SiO}_{2}$ embedded $\mathrm{TiO}_{2}$ mesoporous film, and 20 vol\% $470 \mathrm{~nm} \mathrm{Ag} @ \mathrm{SiO}_{2}$ embedded $\mathrm{TiO}_{2}$ mesoporous film. The area of the film is $5 \times 5 \mathrm{~mm}^{2}$.

the nanostructure, an extra broadening of the surface plasmon peaks occurs. $^{36}$

In order to fabricate the photoelectrode of DSSCs, the aqueous solution of the core-shell particles was mixed with the slurry of $\mathrm{TiO}_{2}$ nanoparticles which were prepared using the hydrothermal method. The mixture slurry was pasted on fluorine doped tin oxide (FTO) coated glass and thermally annealed. Fig. 3 presents SEM micrographs of $\mathrm{TiO}_{2}$ mesoporous films embedded with the core-shell particles. It clearly shows that large core-shell particles with an average diameter of $110 \mathrm{~nm}$ or $470 \mathrm{~nm}$ are uniformly dispersed in the $\mathrm{TiO}_{2}$ nanoparticle matrix. Furthermore, the distance between the outer surfaces of the core-shell particles in Fig. 3 quantitatively fits well with the calculated one, which is about $42 \mathrm{~nm}$ for $20 \mathrm{vol} \% 110 \mathrm{~nm}$ core-shell particle added film, and $178 \mathrm{~nm}$ for 20 vol\% $470 \mathrm{~nm}$ core-shell particle added film. Fig. 3E shows the optical micrograph of pure $\mathrm{TiO}_{2}$ film and composite films coated fluorine doped tin oxide (FTO) substrates. From top to bottom, the film is composed of pure $\mathrm{TiO}_{2}, \mathrm{TiO}_{2} / 20$ vol\% $110 \mathrm{~nm}$ core-shell particles, and $\mathrm{TiO}_{2} / 20$ vol\% $470 \mathrm{~nm}$ core-shell particles. A change in the color of the film proves that the addition of the plasmonic particles influences the optical property of the mesoporous films. The silver phase in the mixture film is well crystallized during a thermal annealing procedure. In addition, a stronger intensity of silver XRD peaks for the $110 \mathrm{~nm}$ core-shell particle added film, is due to the higher surface area of smaller core-shell particles.

The light absorption and scattering properties of the $\mathrm{TiO}_{2}$ based composite films with $110 \mathrm{~nm}$ or $470 \mathrm{~nm}$ diameter $\mathrm{Ag} @ \mathrm{SiO}_{2}$ core-shell particles are shown in Fig. 4. Since the refractive index of $\mathrm{TiO}_{2}(n \approx 2.3)$ surrounding the core-shell particles is larger than that of water, the peaks of the spectra


Fig. 4 Experimental (A) UV-vis absorbance and (B) reflectance spectra of pure $\mathrm{TiO}_{2}$ film, $\mathrm{TiO}_{2} / 110$ nm Ag@ $\mathrm{SiO}_{2}$ composite film, and $\mathrm{TiO}_{2} / 470$ nm Ag@ $\mathrm{SiO}_{2}$ composite film.

shift to a longer wavelength. A long tail of the absorbance spectra of the composite films may result from the overlapping of the elementary plasmon peaks of the core-shell particles. In addition to the absorption, the scattering behavior of the composite films is also measured. Larger core-shell particles display a stronger scattering effect over red and IR light and smaller core-shell particles cause a higher absorption over green and orange light. A change in the relative magnitude of absorption and scattering by different core-shell particles qualitatively agrees with the theoretical predictions in Fig. 2B. As the core size increases from $90 \mathrm{~nm}$ to $450 \mathrm{~nm}$, the surface plasmons peak of the nanoshell shifts to a longer wavelength and the scattering efficiency of the plasmonic particles in the near IR regime increases.

The mixture films were dipped in the solution of dye molecules (N719 or black dye). The absorption spectra of adsorbed dye molecules are shown in Fig. S1, ESI.† For this measurement, sensitized thick films were immersed in $\mathrm{NaOH}$ 

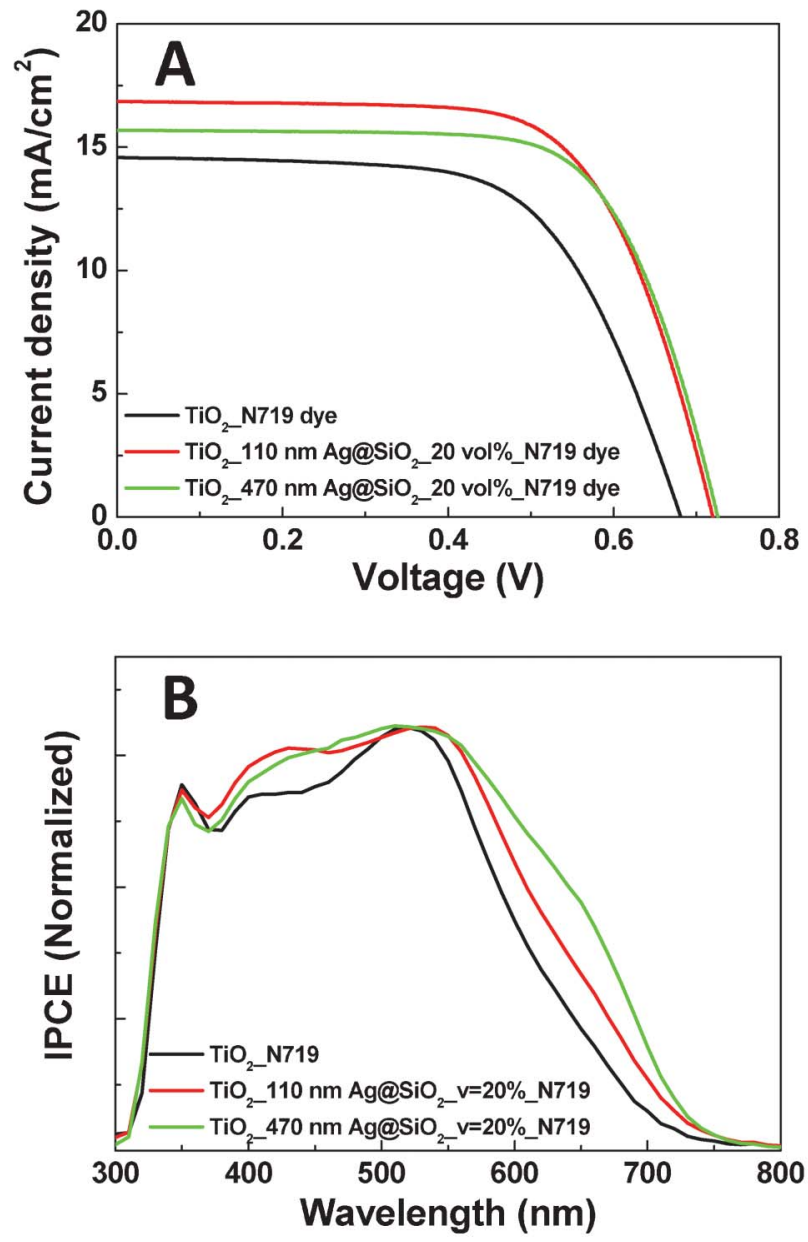

Fig. $5 \mathrm{~J}-V$ curve and IPCE of DSSCS. (A) Comparison of the $J-V$ curves of N719 dye sensitized solar cells containing $\mathrm{TiO}_{2}$ film, 20 vol\% 110 nm Ag@SiO 2 core-

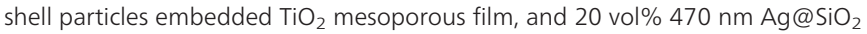
core-shell particles embedded $\mathrm{TiO}_{2}$ mesoporous film. (B) Normalized IPCE curves of N719 dye sensitized solar cells containing $\mathrm{TiO}_{2}$ film, 20 vol\% $110 \mathrm{~nm}$ $\mathrm{Ag} @ \mathrm{SiO}_{2}$ core-shell particles embedded $\mathrm{TiO}_{2}$ mesoporous film, and 20 vol\% 470 nm Ag@ $\mathrm{SiO}_{2}$ core-shell particles embedded $\mathrm{TiO}_{2}$ mesoporous film.

solution to separate the dyes from the photoelectrode. The amount of adsorbed dye molecules in Fig. S1, ESI $\dagger$ is consistent with the ideal surface area ratio of the photoelectrode, which suggests that the dye molecules are uniformly coated on both $\mathrm{TiO}_{2}$ and core-shell particles of the photoelectrode. This surface passivation of the core-shell particles by dye molecules plays the role of a capping layer and improves the chemical stability of the silver shell. ${ }^{31}$ Fig. S2, ESI $\dagger$ shows the effect of the dye coating on the corrosion resistance of the core-shell particles. UV/Vis absorbance spectra of the N719 dye or black dye coated $\mathrm{TiO}_{2}$-core-shell composite films did not show a change after they were immersed in the electrolyte for 1 day. Some increase in the blue region in the electrolytedipped sample is due to a small amount of the residual electrolyte attached to the films. This result supports the chemical stability of the dye coated Ag nanoshell in the electrolyte.
Table 1 Photovoltaic performance of DSSCs based on different films with different dyes

\begin{tabular}{|c|c|c|c|c|c|}
\hline Film & Dye & $J_{\mathrm{sc}}\left(\mathrm{mA} \mathrm{cm}{ }^{-2}\right)$ & $V_{\mathrm{oc}}(\mathrm{V})$ & $\mathrm{FF}$ & $\eta(\%)$ \\
\hline $\mathrm{TiO}_{2}$ & N719 dye & 14.6 & 0.68 & 0.63 & 6.2 \\
\hline $\mathrm{TiO}_{2} / 110$ nm Ag@SiO 2 & N719 dye & 16.8 & 0.72 & 0.67 & 8.1 \\
\hline $\mathrm{TiO}_{2} / 470$ nm Ag@SiO 2 & N719 dye & 15.7 & 0.73 & 0.69 & 7.9 \\
\hline $\mathrm{TiO}_{2} / 90 \mathrm{~nm} \mathrm{SiO}{ }_{2}$ & N719 dye & 11.6 & 0.72 & 0.70 & 5.9 \\
\hline $\mathrm{TiO}_{2} / 450 \mathrm{~nm} \mathrm{SiO}{ }_{2}$ & N719 dye & 12.3 & 0.70 & 0.71 & 6.1 \\
\hline $\mathrm{TiO}_{2}$ & Black dye & 7.4 & 0.63 & 0.72 & 3.4 \\
\hline $\mathrm{TiO}_{2} / 110$ nm Ag@SiO 2 & Black dye & 9.0 & 0.70 & 0.70 & 4.4 \\
\hline $\mathrm{TiO}_{2} / 470$ nm Ag@SiO & Black dye & 11.7 & 0.70 & 0.72 & 5.9 \\
\hline
\end{tabular}

DSSCs were built on dye-coated composite films with a thickness of $7 \mu \mathrm{m}$. N719dye is a widely used dye. Compared with N719, the absorption spectrum of black dye is larger toward the red and infrared regime, but the optical cross section of black dye over green light is smaller. ${ }^{37,38}$ Therefore, N719 and black dye are expected to differently respond to 110 $\mathrm{nm}$ and $470 \mathrm{~nm}$ core-shell particles. Fig. 5A and 5B show $J-V$ curve and incident photon to current efficiency (IPCE) spectra of DSSCs employing N719 dye. They clearly indicate that the addition of $\mathrm{Ag} @ \mathrm{SiO}_{2}$ particles enhances the energy conversion efficiency of DSSCs, although the amount of adsorbed dye molecules is decreased in $\mathrm{Ag} @ \mathrm{SiO}_{2}$ particle added photoelectrodes. $470 \mathrm{~nm}$ core-shell particles into $\mathrm{TiO}_{2}$ films increases the short circuit current $\left(J_{\mathrm{sc}}\right)$ from $14.6 \mathrm{~mA} \mathrm{~cm}^{-2}$ to $15.7 \mathrm{~mA}$ $\mathrm{cm}^{-2}$ (Table 1). This enhancement was more pronounced when $110 \mathrm{~nm}$ core-shell particles were added.

The IPCE spectra of DSSCs in Fig. 5B show that $\mathrm{Ag} @ \mathrm{SiO}_{2}$ particles increase photon-electron conversion efficiency in two ways. Increases in absorption for shorter wavelength regime and scattering for longer wavelength regime enlarge effective light intensity near dye molecules and enhance photocurrent generation. It is noted that $110 \mathrm{~nm}$ core-shell particles improve the photocurrent generation more effectively in the shorter wavelength range and that $470 \mathrm{~nm}$ core-shell particles work better in the longer wavelength range. At the wavelength of $650 \mathrm{~nm}$, the normalized IPCE is very dependent on the size of the Ag nanoshell. A difference in the improvement of IPCE spectra by two kinds of core-shell particles agrees well with their different spectral response shown in Fig. 2. This indicates that a change in the geometric factor of the coreshell particles can be used to tune the photon-electron conversion process of the solar cells.

Since $20 \mathrm{vol} \%$ of the composite film was occupied by large core-shell particles, the surface area of the mixture film for dye absorption also decreased by almost $20 \%$. In order to show the real improvement of the cell performance after employing core-shell particles, a control experiment was conducted using composite films containing the same amount of bare silica particles without a silver layer coating. Both the $J-V$ curve and the IPCE show a dramatic decrease in cell performance (Fig. S3, ESI $\dagger$ ), due to the decreased total surface area for dye absorption. This indicates that it is mainly the plasmonic Ag nanoshell enhancing the performance of DSSCs. 

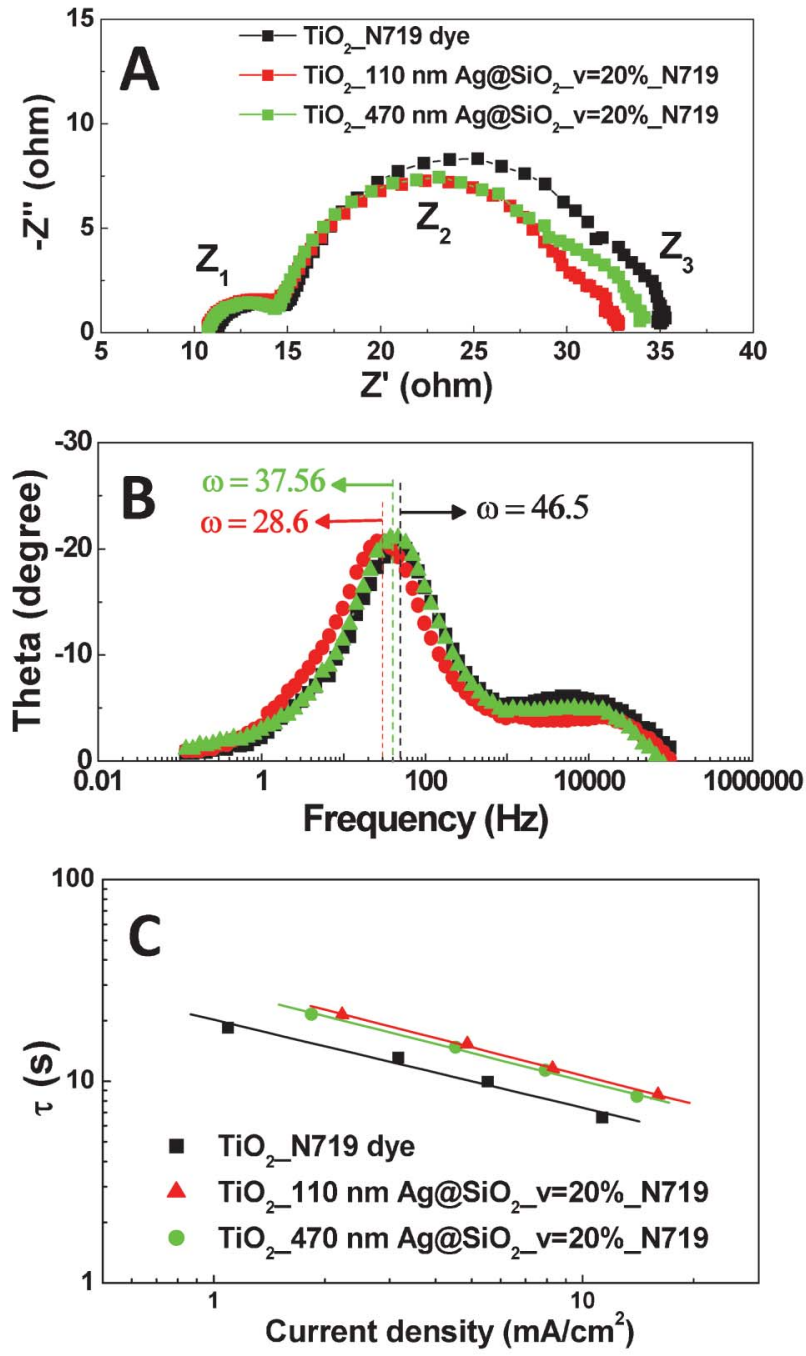

Fig. 6 (A) Nyquist plots and (B) Bode plots of DSSCs with N719 dye. (C) lifetime vs. Isc $_{\text {sc }}$ plots of DSSCs with N719 dye.

It is noted that the core-shell particles in the photoelectrode also increase open circuit voltage $\left(V_{\text {oc }}\right)$ of DSSCs. Electrochemical impedance spectrum (EIS) analysis and the SLIM-PCV method were performed to understand the difference in charge recombination rate and electron lifetime for core-shell particle embedded DSSCs and reference cells. Fig. 6A shows the Nyquist plots of the DSSCs. The core-shell particles decrease a semi-circle of the impedance spectrum in the frequency regime of $10^{\circ}-10^{3} \mathrm{~Hz}\left(\omega_{3}\right)$, which corresponds to the impedance at the $\mathrm{TiO}_{2} /$ dye/electrolyte interface of DSSCs. ${ }^{39}$ This is because the surface plasmon can enhance the injected electron density of the conduction band of $\mathrm{TiO}_{2}$ nanoparticles. In addition, in Fig. 6B, Bode plots show that a frequency of maximum impedance in the $\omega_{3}$ region shifts to a lower frequency region when the core-shell particles are added to DSSCs. This indicates that the carrier lifetime $(\tau)$ is increased by adding the core-shell particles. A plot of lifetime $v s . J_{\mathrm{sc}}$ in Fig. 6C also exhibits that the core-shell particles increase carrier lifetime. This is attributed to suppressed carrier
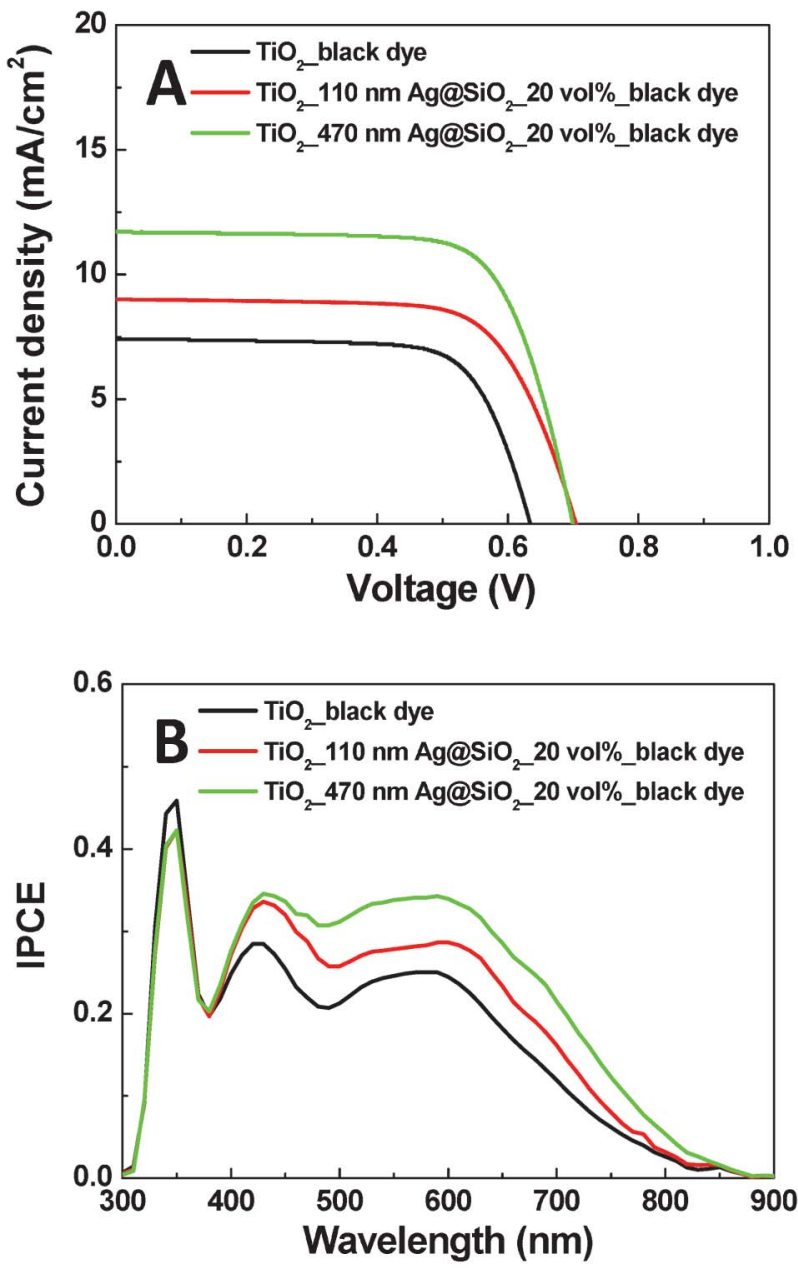

Fig. $7 \mathrm{~J}-V$ curve and IPCE of DSSCS. (A) Comparison of the $J-V$ curves of black dye sensitized solar cells containing $\mathrm{TiO}_{2}$ film, 20 vol\% 110 nm Ag@ $\mathrm{SiO}_{2}$ coreshell particles embedded $\mathrm{TiO}_{2}$ mesoporous film, and 20 vol\% 470 nm Ag@ $\mathrm{SiO}_{2}$ core-shell particles embedded $\mathrm{TiO}_{2}$ mesoporous film. (B) Comparison of the IPCE curves of black dye sensitized solar cells containing $\mathrm{TiO}_{2}$ film, 20 vol\% 110 nm Ag@ $@ \mathrm{SiO}_{2}$ core-shell particles embedded $\mathrm{TiO}_{2}$ mesoporous film, and 20 vol\% 470 nm Ag@ $\mathrm{SiO}_{2}$ core-shell particles embedded $\mathrm{TiO}_{2}$ mesoporous film.

recombination by insulating silica cores and the Schottky barrier at the $\mathrm{TiO}_{2} / \mathrm{Ag}$ shell interface. ${ }^{22,40,41}$ This Schottky barrier prohibits the photo-generated electron transferring from $\mathrm{TiO}_{2}$ to $\mathrm{Ag}$ nanoshell, so it can suppress carrier trapping and recombination by the silver nanoshell.

The enhanced photon-electron conversion by the coreshell particles is more clearly observed in black dye DSSCs. The light absorption ability of black dye molecules is smaller than that of the N719 dye, due to the low extinction coefficient and surface coverage of black dye. ${ }^{38}$ Therefore, the role of core-shell particles in the light harvesting is more critical in black dye DSSCs than in N719 DSSCs. As shown in Fig. 7A, $J_{\mathrm{sc}}$ of typical black dye DSSCs increases from $7.4 \mathrm{~mA} \mathrm{~cm}^{-2}$ to 9.0 $\mathrm{mA} \mathrm{cm} \mathrm{cm}^{-2}$ when $110 \mathrm{~nm}$ core-shell particles are added into $\mathrm{TiO}_{2}$ mesoporous films. The increase in $J_{\mathrm{sc}}$ is more dramatic when the same amount of $470 \mathrm{~nm}$ core-shell particles is added. $J_{\mathrm{sc}}$ reaches to $11.7 \mathrm{~mA} \mathrm{~cm}^{-2}$ for the larger core-shell 
particle added black dye DSSCs (Table 1). Better performance of $470 \mathrm{~nm}$ core-shell particles in black dye DSSCs is traced to the fact that the absorption and scattering spectra of larger core-shell particles are pushed to a longer wavelength range where black dye works better than N719 dye. $V_{\text {oc }}$ of the coreshell particle embedded DSSCs is slightly larger than that of a control sample of pure $\mathrm{TiO}_{2}$ nanoparticle based DSSCs, which is similar to the core-shell particle added N719 dye. Given that the addition of $20 \mathrm{vol} \%$ core-shell particles decreases the amount of adsorbed dye almost by $20 \%$, an increase in $J_{\text {sc }}$ from $7.4 \mathrm{~mA} \mathrm{~cm}^{-2}$ to $11.7 \mathrm{~mA} \mathrm{~cm}{ }^{-2}$ indicates that the core-shell particles of $470 \mathrm{~nm}$ can improve the cross section of black dye in DSSCs by a factor of two. In these high efficiency DSSCs consisting of black dye and core-shell particles, aging or corrosion is negligibly observed.

Fig. 7B shows the IPCE spectra of black dye DSSCs. Both 110 $\mathrm{nm}$ and $470 \mathrm{~nm}$ core-shell particles increase the photonelectron energy conversion efficiency. Compared with $110 \mathrm{~nm}$ particles, a uniform increase in IPCE is observed in the range of $500 \mathrm{~nm}$ to $800 \mathrm{~nm}$ where larger core-shell particles cause higher scattering and absorption of incoming light. This reveals that the enhanced photocurrent generation of black dye DSSCs is correlated to the enhanced scattering and absorption by the core-shell particles. The performance of DSSCs using black dye as the sensitizer exemplifies the benefit of the tuning capability of the Ag nanoshell. Compared with N719, which is widely used in dye sensitized solar cells, the black dye has an advantage of a broad light absorption spectrum. Black dye can collect more photons in red and infrared light than N719 dye, which can increase the theoretical energy conversion efficiency of the dye sensitized solar cells (DSSCs). However, black dye has the critical problem of a small optical cross section and weak surface coverage. Hence, DSSCs with black dye should employ a very thick photoelectrode to absorb a large enough amount of solar light. The thick photoelectrode is likely to prevent the electron transport, which, in turn, reduces the energy conversion efficiency of DSSCs greatly below the theoretical limit. Results in Fig. 7 attest that the Ag nanoshell can solve the problem of the small optical cross section of black dye and increase the theoretical limit of DSSCs.

\section{Conclusion}

We have successfully incorporated the metallic nanoshelldielectric core particles with strong surface plasmon resonance into DSSCs. Light absorption and scattering in the visible range is significantly enhanced in the photoelectrodes containing core-shell particles with various core sizes that depend on the size of the core-shell particles. As the size of the core increases, light interacts with the surface plasmons of the core-shell particles in the longer wavelength regime. The coreshell particles enhance the optical cross section of dye sensitizers coated onto the photoelectrode and increase the energy conversion efficiency of DSSCs. The enhanced photonelectron conversion is attributed to localized surface plasmons of the core-shell particles, which increase the absorption and scattering of the incoming light in the photoelectrode. Tuning of the surface plasmons' frequency with different sensitizing dyes is also found to benefit the energy conversion efficiency of DSSCs. When the extinction spectrum of the plasmonic particles is overlaid with the absorption spectrum of black dye with a small optical cross section, the short circuit current of DSSCs is almost doubled, with a negligible change in the open circuit voltage. Our results demonstrate a simple method for enhancing the light absorption of various dyes with different light absorption spectra, via the surface plasmons.

\section{References}

1 W. L. Barnes, A. Dereux and T. W. Ebbesen, Surface Plasmon Subwavelength Optics, Nature, 2003, 424, 824-830.

2 H. Wang, G. P. Goodrich, F. Tam, C. Oubre, P. Nordlander and N. J. Halas, Controlled Texturing Modifies the Surface Topography and Plasmonic Properties of Au Nanoshells, $J$. Phys. Chem. B, 2005, 109, 11083-11087.

3 A. Polman, Plasmonics Applied, Science, 2008, 322, 868-869.

4 T. C. Preston and R. Signorell, Growth and Optical Properties of Gold Nanoshells Prior to the Formation of a Continuous Metallic Layer, ACS Nano, 2009, 3, 3696-3706.

5 H. Wei, A. Reyes-Coronado, P. Nordlander, J. Aizpurua and H. X. Xu, Multipolar Plasmon Resonances in Individual Ag Nanorice, ACS Nano, 2010, 4, 2649-2654.

6 J. Zuloaga, E. Prodan and P. Nordlander, Quantum Plasmonics: Optical Properties and Tunability of Metallic Nanorods, ACS Nano, 2010, 4, 5269-5276.

7 S. J. Oldenburg, R. D. Averitt, S. L. Westcott and N. J. Halas, Nanoengineering of Optical Resonances, Chem. Phys. Lett., 1998, 288, 243-247.

8 E. Prodan, P. Nordlander and N. J. Halas, Electronic Structure and Optical Properties of Gold Nanoshells, Nano Lett., 2003, 3, 1411-1415.

9 S. Lal, S. Link and N. J. Halas, Nano-Optics from Sensing to Waveguiding, Nat. Photonics, 2007, 1, 641-648.

10 F. Le, D. W. Brandl, Y. A. Urzhumov, H. Wang, J. Kundu, N. J. Halas, J. Aizpurua and P. Nordlander, Raman Scattering and Surface-Enhanced Infrared Absorption, ACS Nano, 2008, 2, 707-718.

11 S. A. Love, B. J. Marquis and C. L. Haynes, Recent Advances in Nanomaterial Plasmonics: Fundamental Studies and Applications, Appl. Spectrosc., 2008, 62, 346A-362A.

12 C. Loo, A. Lowery, N. J. Halas, J. West and R. Drezek, Immunotargeted Nanoshells for Integrated Cancer Imaging and Therapy, Nano Lett., 2005, 5, 709-711.

13 L. R. Hirsch, R. J. Stafford, J. A. Bankson, S. R. Sershen, B. Rivera, R. E. Price, J. D. Hazle, N. J. Halas and J. L. West, Nanoshell-Mediated Near-Infrared Thermal Therapy of Tumors under Magnetic Resonance Guidance, Proc. Natl. Acad. Sci. U. S. A., 2003, 100, 13549-13554.

14 S. R. Sershen, S. L. Westcott, N. J. Halas and J. L. West, Temperature-Sensitive Polymer-Nanoshell Composites for Photothermally Modulated Drug Delivery, J. Biomed. Mater. Res., 2000, 51, 293-298. 
15 H. A. Atwater and A. Polman, Plasmonics for Improved Photovoltaic Devices, Nat. Mater., 2010, 9, 205-213.

16 B. O’Regan, M. Grätzel and A. Low-Cost, High-Efficiency Solar Cell Based on Dye-Sensitized Colloidal $\mathrm{TiO}_{2}$ Films, Nature, 1991, 353, 737-740.

17 A. J. Frank, N. Kopidakis and J. V. Lagemaat, Electrons in Nanostructured $\mathrm{TiO}_{2}$ Solar Cells: Transport, Recombination and Photovoltaic Properties, Coord. Chem. Rev., 2004, 248, 1165-1179.

18 C. Y. Chen, M. Wang, J. Y. Li, N. Pootrakulchote, L. Alibabaei, C. Ngoc-le, J. D. Decoppet, J. H. Tsai, C. Grätzel, C. G. Wu, S. M. Zakeeruddin and M. Grätzel, Highly Efficient Light-Harvesting Ruthenium Sensitizer for Thin-Film Dye-Sensitized Solar Cells, ACS Nano, 2009, 3, 3103-3109.

19 L. Li, Y. Hao, X. Yang, J. Zhao, H. Tian, C. Teng, A. Hagfeldt and L. Sun, A Double-Band Tandem Organic Dye-Sensitized Solar Cell with an Efficiency of 11.5\%, ChemSusChem, 2011, 4, 609-612.

20 C. Y. Huang, Y. C. Hsu, J. G. Chen, V. Suryanarayanan, K. M. Lee and K. C. Ho, The Effects of Hydrothermal Temperature and Thickness of $\mathrm{TiO}_{2}$ Film on the Performance of a Dye-Sensitized Solar Cell, Sol. Energy Mater. Sol. Cells, 2006, 90, 2391-2397.

21 M. G. Kang, K. S. Ryu, S. H. Chang, N. G. Park, J. S. Hong and K. J. Kim, Dependence of $\mathrm{TiO}_{2}$ Film Thickness on Photocurrent-Voltage Characteristics of Dye-Sensitized Solar Cell, Bull. Korean Chem. Soc., 2004, 25, 742-744.

22 C. S. Chou, R. Y. Yang, C. K. Yeh and Y. J. Lin, Preparation of $\mathrm{TiO}_{2}$ /Nano-Metal Composite Particles and Their Applications in Dye-Sensitized Solar Cells, Powder Technol., 2009, 194, 95-105.

23 S. D. Standridge, G. C. Schatz and J. T. Hupp, Distance Dependence of Plasmon-Enhanced Photocurrent in DyeSensitized Solar Cells, J. Am. Chem. Soc., 2009, 131, 8407-8409.

24 M. D. Brown, T. Suteewong, R. S. S. Kumar, V. D’Innocenzo, A. Petrozza, M. M. Lee, U. Wiesner and H. J. Snaith, Plasmonic Dye-Sensitized Solar Cells Using Core-Shell Metal-Insulator Nanoparticles, Nano Lett., 2011, 11, 438-445.

25 J. F. Qi, X. N. Dang, P. T. Hammond and A. M. Belcher, Highly Efficient Plasmon-Enhanced Dye-Sensitized Solar Cells through Metal@Oxide Core-Shell Nanostructure, ACS Nano, 2011, 5, 7108-7116.

26 M. Grätzel, Perspectives for Dye-Sensitized Nanocrystalline Solar Cells, Prog. Photovolt, Res. Appl., 2000, 8, 171-185.

27 K. Hara, T. Nishikawa, M. Kurashige, H. Kawauchi, T. Kashima, K. Sayama, K. Aika and H. Arakawa, Influence of Electrolyte on the Photovoltaic Performance of a Dye-Sensitized TiO2 Solar Cell Based on a Ru(II) terpyridyl Complex Photosensitizer, Sol. Energy Mater. \& Sol. Cells, 2005, 85, 21-30.

28 S. Altobello, R. Argazzi, S. Caramori, C. Contado, S. D. Fre, P. Rubino, C. Chone, G. Larramona and C. A. Bignozzi, Sensitization of Nanocrystalline $\mathrm{TiO}_{2}$ with Black Absorbers Based on Os and RuPolypyridine Complexes, J. Am. Chem. Soc., 2005, 127, 15342-15343.

29 Z. S. Wang, Y. Cui, Y. Dan-oh, C. Kasada, A. Shinpo and K. Hara, Thiophene-Functionalized Coumarin Dye for Efficient Dye-Sensitized Solar Cell: Electron Lifetime
Improved by Coadsorption of Deoxycholic Acid, J. Phys. Chem. C, 2007, 111, 7224-7230.

30 S. Chang, Q. Li, X. Xiao, K. W. Wong and T. Chen, Enhancement of Low Energy Sunlight Harvesting in Dyesensitized Solar Cells Using Plasmonic Gold Nanorods, Energy Environ. Sci., 2012, 5, 9444-9448.

31 B. Ding, B. J. Lee, M. J. Yang, H. S. Jung and J. K. Lee, Surface-Plasmon Assisted Energy Conversion in DyeSensitized Solar Cells, Adv. Energy Mater., 2011, 1, 415-421.

32 R. D. Averitt, D. Sarkar and N. J. Halas, Plasmon Resonance Shifts of Au-Coated Au2S Nanoshells: Insight into Multicomponent Nanoparticle Growth, Phys. Rev. Lett., 1997, 78, 4217-4220.

33 Z. S. Wang, H. Kawauchi, T. Kashima and H. Arakawa, Significant Influence of $\mathrm{TiO}_{2}$ Photoelectrode Morphology on the Energy Conversion Efficiency of N719 Dye-Sensitized Solar Cell, Coord. Chem. Rev., 2004, 248, 1381-1389.

34 D. D. Smith and K. A. Fuller, Photonic Bandgaps in Mie Scattering by Concentrically Stratified Spheres, J. Opt. Soc. Am. B, 2002, 19, 2449-2455.

35 A. Vial and T. Laroche, Description of Dispersion Properties of Metals by Means of theCritical Points Model and Application to the Study of Resonant Structures Using the FDTD Method, J. Phys. D: Appl. Phys., 2007, 40, 7152-7158.

36 U. Kreibig and M. Vollmer, Optical Properties of Metal Clusters, Springer, New York, 1995.

37 M. K. Nazeeruddin, A. Kay, I. Rodicio, R. Humphry-Baker, E. Muller, P. Liska, N. Vlachopoulos and M. Grätzel, Conversion of Light to Electricity by cis- $\mathrm{X}_{2}$ bis(2,2'-bipyridyl4,4'-dicarboxylate)ruthenium(II) Charge-Transfer Sensitizers $\left(\mathrm{X}=\mathrm{Cl}^{-}, \mathrm{Br}^{-}, \mathrm{I}^{-}, \mathrm{CN}^{-}\right.$, and $\mathrm{SCN}^{-}$) on Nanocrystalline $\mathrm{TiO}_{2}$ Electrodes, J. Am. Chem. Soc., 1993, 115, 6382-6390.

38 M. K. Nazeeruddin, P. Pechy, T. Renouard, S. M. Zakeeruddin, R. Humphry-Baker, P. Comte, P. Liska, L. Cevey, E. Costa, V. Shklover, L. Spiccia, G. B. Deacon, C. A. Bignozzi and M. Grätzel, Engineering of Efficient Panchromatic Sensitizers for Nanocrystalline $\mathrm{TiO}_{2}$-Based Solar Cells, J. Am. Chem. Soc., 2001, 123, 1613-1624.

39 S. Lee, I. S. Cho, J. H. Lee, D. H. Kim, D. W. Kim, J. Y. Kim, H. Shin, J. K. Lee, H. S. Jung, N. G. Park, K. Kim, M. J. Ko and K. S. Hong, Chem. Mater., 2010, 22, 1958-1965.

40 F. Huang, D. Chen, X. L. Zhang, R. A. Caruso and Y. B. Cheng, Dual-Function Scattering Layer of Submicrometer-Sized Mesoporous $\mathrm{TiO}_{2}$ Beads for HighEfficiency Dye-Sensitized Solar Cells, Adv. Funct. Mater., 2010, 20, 1301-1305.

41 J. K. Lee, B. H. Jeong, S. I. Jang, Y. S. Yeo, S. H. Park, J. U. Kim, Y. G. Kim, Y. W. Jang and M. R. Kim, Multi-Layered $\mathrm{TiO}_{2}$ Nanostructured Films for Dye-Sensitized Solar Cells, $J$. Mater. Sci.: Mater. Electron., 2009, 20, 446-450.

42 W. Stöber, A. Fink and E. Bohn, Controlled Growth of Monodisperse Silica Spheres in Micron Size Range, $J$. Colloid Interface Sci., 1968, 26, 62-69.

43 A. Zaban, S. Ferrere, J. Sprague and B. A. Gregg, pHDependent Redox Potential Induced in a Sensitizing Dye by Adsorption onto $\mathrm{TiO}_{2}$, J. Phys. Chem. A, 1997, 101, 55-57.

44 N. G. Park, K. M. Kim, M. G. Kang, K. S. Ryu, S. H. Chang and Y. J. Shin, Chemical Sintering of Nanoparticles: A Methodology for Low-Temperature Fabrication of DyeSensitized $\mathrm{TiO}_{2}$ Films, Adv. Mater., 2005, 17, 2349-2353. 